\title{
Piezoelectric Properties of Mg Doped ZnO Thin Film using Sol-Gel Method and Spin Coating
}

\author{
N.S. Ab Sukor' ${ }^{1}$ A.G.E. Sutjipto", A. Shaitir and M.A. Jusoh ${ }^{1}$ \\ ${ }^{1}$ Faculty of Industrial Sciences and Technology, Universiti Malaysia Pahang, Lebihraya Tun Razak, 26300 Gambang, Pahang, Malaysia.
}

ABSTRACT - This reports about the synthesis of Mg doped ZnO thin film using spin-coating techniques through sol-gel method. For studying piezoelectric properties, optical properties and morphology, the prepared $\mathrm{Mg}$ doped $\mathrm{ZnO}$ thin film samples were characterized using UltravioletVisible Spectroscopy (UV-Vis), Photoluminescence Spectroscopy (PL), X-ray Diffraction (XRD), Field Emission Scanning Electron Microscope (FESEM) and Ultrasonic Vibrator. The particle size was evaluated using Scherrer's formula from XRD patterns. The results show the crystallite size decreased with increasing Mg concentrations. The optical properties showed that sample exhibit a blue shift in absorption in UV spectra indicating good optical properties. The morphology of grain size microstructure was observed from FESEM with results the grain size of the samples decreased with increasing $\mathrm{Mg}$ doping. The piezoelectric properties were evaluated using ultrasonic vibrator and multimeter to obtain potential difference for each sample. The results obtained that potential difference increase with increasing Mg contents and higher rotation of spin speed was used.

\section{ARTICLE HISTORY}

Received: $6^{\text {th }}$ July 2020

Revised: $2^{\text {nd }}$ Nov 2020

Accepted: 31 st Jan 2021

\section{KEYWORDS}

Thin film

Nanotechnology

$\mathrm{ZnO}$

$\mathrm{Mg}$ doped $\mathrm{ZnO}$

Sol-gel

Mg doping

\section{INTRODUCTION}

Zinc oxide $(\mathrm{ZnO})$ is a versatile material containing a vast range of properties, including good transparency, high thermal conductivity, room-temperature solid luminescence, high electron mobility, and wide band gap. It can be used in many application devices such as laser diodes, solar cell, gas sensors, light-emitting diodes (LED), surface acoustic waves, thin-film transistors (TFT), and field emission devices [1]. The transparent oxide semiconductor is suitable in transparent and flexible electronics. The $\mathrm{ZnO}$ has excellent semiconducting properties, which has a direct wide band gap of $3.37 \mathrm{eV}$ lying near UV range and large excitation binding energy of $60 \mathrm{meV}$ at room temperature for optoelectronics device fabrication. Metal-doped $\mathrm{ZnO}$ and $\mathrm{ZnO}$ have good optical and electrical properties as $\mathrm{ZnO}$ doped with a metal such as magnesium improves oxide semiconductors' electrical performance [2].

There are various techniques (vacuum and non-vacuum) to synthesis $\mathrm{ZnO}$ thin film, such as chemical vapour deposition (CVD), sputtering, molecular beam epitaxy (MBE), sol-gel process, pulse laser deposition (PLD), and spray pyrolysis. On the other hand, the sol-gel method using spin coating techniques is used because of its ease to dope, simplicity, flexibility, acceptable cost and offers to prepare large-area coating but might give the low crystalline quality of $\mathrm{ZnO}$ thin film. However, some significant challenges using this process, such as difficulties in preparing a stable dispersion, poor conductivity of $\mathrm{ZnO}$ thin films, and uniformity in the coating process [3]. The objectives of this work are to synthesis $\mathrm{Mg}$ doped $\mathrm{ZnO}$ thin film using the sol-gel method and to fabricate thin film of $\mathrm{Mg}$ doped $\mathrm{ZnO}$ using spin coater, and to characterize the piezoelectricity of the thin film.

\section{METHODOLOGY}

\section{Synthesis of Sol-Gel}

Zinc acetate dehydrate and magnesium chloride were dissolved using absolute ethanol in a beaker. The mixture of the solution was stirred by using a magnetic stirrer at $60{ }^{\circ} \mathrm{C}$ for 1 hour. The colour of the solution was changed from clear to milky. After one hour, a few drops of diethanolamine (DEA) were added to the mixture until the milky solution turns clear using a dropper. Then, the mixture of the solution was left to continue stirred for another 1 hour. After one hour, a homogenous sol-gel was sealed with parafilm and then deposited for 48 hours.

\section{Fabrication of Mg doped ZnO Thin Film}

Pure $\mathrm{ZnO}$ and $\mathrm{Mg}$ doped $\mathrm{ZnO}$ thin films were fabricated onto a glass substrate and aluminium foil through spin coating techniques by varying spin speed. In this work, Laurell WS-650MZ-23 Spin Coater was used to fabricate the thin films. The thin films were fabricated with different spin speeds with a spinning time of 60 second. After one layer of coating, the sample were heated at $80{ }^{\circ} \mathrm{C}$ on a hot plate. The process was repeated for 50 times to obtain 50 layers of coating. In this study, $10 \mathrm{wt} \%$ and $15 \mathrm{wt} \% \mathrm{Mg}$ doped $\mathrm{ZnO}$ were fabricated at $2000 \mathrm{rpm}$, while the $5 \mathrm{wt} \%$ mixture were fabricated with different spin speeds of 2000, 2500 and $3000 \mathrm{rpm}$. After the spin coating process, the sample were annealed at a temperature of $400{ }^{\circ} \mathrm{C}$ for one hour using Thermo Scientific Lindberg Blue M box furnace. Lastly, all samples were 
characterized by using XRD, FESEM, UV-Vis, PL and Ultrasonic Vibrator to determine the optical, structural, morphological and piezoelectric properties of thin films.

\section{RESULTS AND DISCUSSION}

\section{Optical Properties}

Optical properties of the sample was obtained using UV-Vis analysis. UV-Vis was carried out to determine the absorption and transmittance spectrum with different $\mathrm{Mg}$ loading and spin rate rotation. Absorbance measurement (A) of the sample in the function of wavelength from $200-900 \mathrm{~nm}$ was measured. The direct bandgap of samples was determined by OriginPro software using the intercept of $(\alpha h v)^{2}$ versus photon energy (hv) plot. The optical bandgap of undoped and doped $\mathrm{ZnO}$ thin films was obtained by calculated using the Tauc relationship (Eq. 1);

$$
\alpha h v=A\left(h v-E_{g}\right)^{n}
$$

where $E_{\mathrm{g}}$ is energy bandgap, $\mathrm{h}$ is Plank's constant in $\mathrm{eV}\left(4.1357 \times 10^{-15} \mathrm{eV} . \mathrm{s}\right), \mathrm{v}$ is the velocity of light $\left(3 \times 10^{8} \mathrm{~m} / \mathrm{s}\right)$ and $\alpha$ is absorption coefficient.

Table 1 shows the optical bandgap of UV emission at different $\mathrm{Mg}$ contents and spin rate. The results show that the optical bandgap value increases with increasing $\mathrm{Mg}$ doping in $\mathrm{ZnO}$ thin films. The results show an increment in bandgap energy as the amount of $\mathrm{Mg}$ dopants increased due to reflectance intensity influences. Perhaps the enhancement in the band gap is due to the incorporation of $\mathrm{Mg}$ and its higher concentration, which moves optical reflection to lower energy and widening the energy gap. The dopant can contribute in the optical band gap of ZnO to the width of the localized states [4]. The results also show that the bandgap energy of thin films increases with increasing spin speed. The film thickness depends on the spin rate as the spin rate of spin coating increases, the thinner the thickness of the film would be produced due to the fluid of sol-gel spins off rapidly at the substrate surfaces [5]. The rapid evaporation of spin coating would induced the lattice strain in grown crystal and also brought to the kinetically driven metastable state phase making the orientation of molecular suitable for charge transport [6].

Table 1. The optical band gap of UV emission at different Mg contents and spin rate

\begin{tabular}{ccc}
\hline $\begin{array}{c}\text { Concentration } \\
\text { of } \mathrm{Mg}(\mathrm{wt} \%)\end{array}$ & $\begin{array}{c}\text { Spin } \\
\text { Speed } \\
(\mathrm{rpm})\end{array}$ & $\begin{array}{c}\text { Optical } \\
\text { Band } \\
\text { gap } \\
(\mathrm{eV})\end{array}$ \\
\hline 0 & 2000 & 3.28 \\
5 & 2000 & 3.13 \\
5 & 2500 & 3.30 \\
5 & 3000 & 3.31 \\
10 & 2000 & 3.32 \\
15 & 2000 & 3.33 \\
\hline
\end{tabular}

Figure 1 shows the transmittance spectrum of different $\mathrm{Mg}$ contents and a spin rate of $\mathrm{Mg}$ doped $\mathrm{ZnO}$ thin films. The results reveal transmittance value of thin films that produced with $0,5,10$ and $15 \mathrm{wt} \% \mathrm{Mg}$ at constant annealing temperature are $91,40,78$ and $82 \%$, respectively. In this study, the trend of transmission graph plotted of $\mathrm{Mg}$ doped $\mathrm{ZnO}$ increases indicate that $\mathrm{Mg}$ doping in $\mathrm{ZnO}$ increased ultra-violet wavelength transmission of $\mathrm{ZnO}$. It shows that the transparency of thin films affected by the concentration of $\mathrm{Mg}$. The transmittance values of 52000, 52500 and 53000 samples are 40,86 and 96\%. Theoretically, the thin film produced will become thinner when spin speed increases during coating and leads to higher transparency. The transmittance value of 86 and $96 \%$ for both 52500 and 53000 indicates that both films could be used in solar cells as transparent conducting oxide electrodes, which is similar to the previous study[5].

\section{Photoluminescence Analysis}

Photoluminescence spectrum is an effective way to study the electronic structure, optical and photochemical properties of semiconductor materials through which knowledge such as surface oxygen vacancies and defects can be obtained, as well as the efficiency of charge carrier trapping, immigration and transfer. Figure 2 shows PL spectra of Mg doped $\mathrm{ZnO}$ thin films with different spin rates and $\mathrm{Mg}$ contents. The result shows show that as $\mathrm{Mg}$ concentration increases, the intensity of the ultraviolet emission bands increase to the maximum at $5 \mathrm{wt} \% \mathrm{Mg}$ doped $\mathrm{ZnO}$, and then decrease at $10 \mathrm{wt} \% \mathrm{Mg}$ doped $\mathrm{ZnO}$ and $15 \mathrm{wt} \% \mathrm{Mg}$ doped $\mathrm{ZnO}$. The intensity decrease due to increasing energy level during doping, thus, reducing the energy bandgap and simultaneously decreasing in recombination rate of electron and hole. 


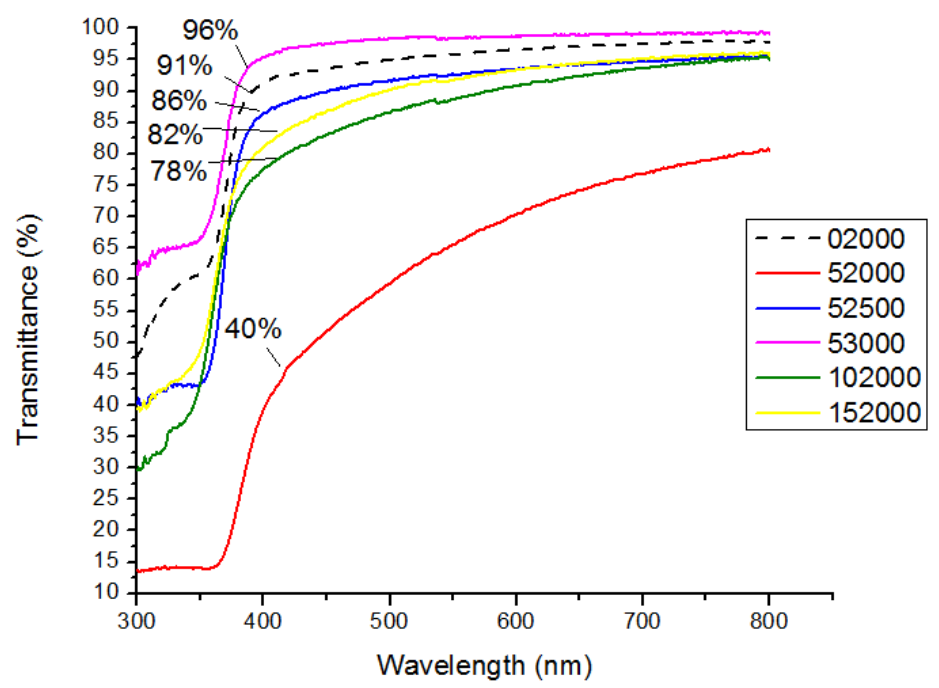

Figure 1. Transmittance spectra of $\mathrm{MgZnO}$ thin films by different $\mathrm{Mg}$ contents and spin rate

The intensity decrease with a higher $\mathrm{Mg}$ concentration as higher doping percent in $\mathrm{ZnO}$ prevents recombination of excited electron and hole. Additional active defect sites would produce inside the $\mathrm{ZnO}$ lattice when higher doping of $\mathrm{Mg}$ content so further adsorption of visible light through active defect sites [2]. The intensity of the ultraviolet emission bands decreased when a higher spin speed was used in the deposition process [7].

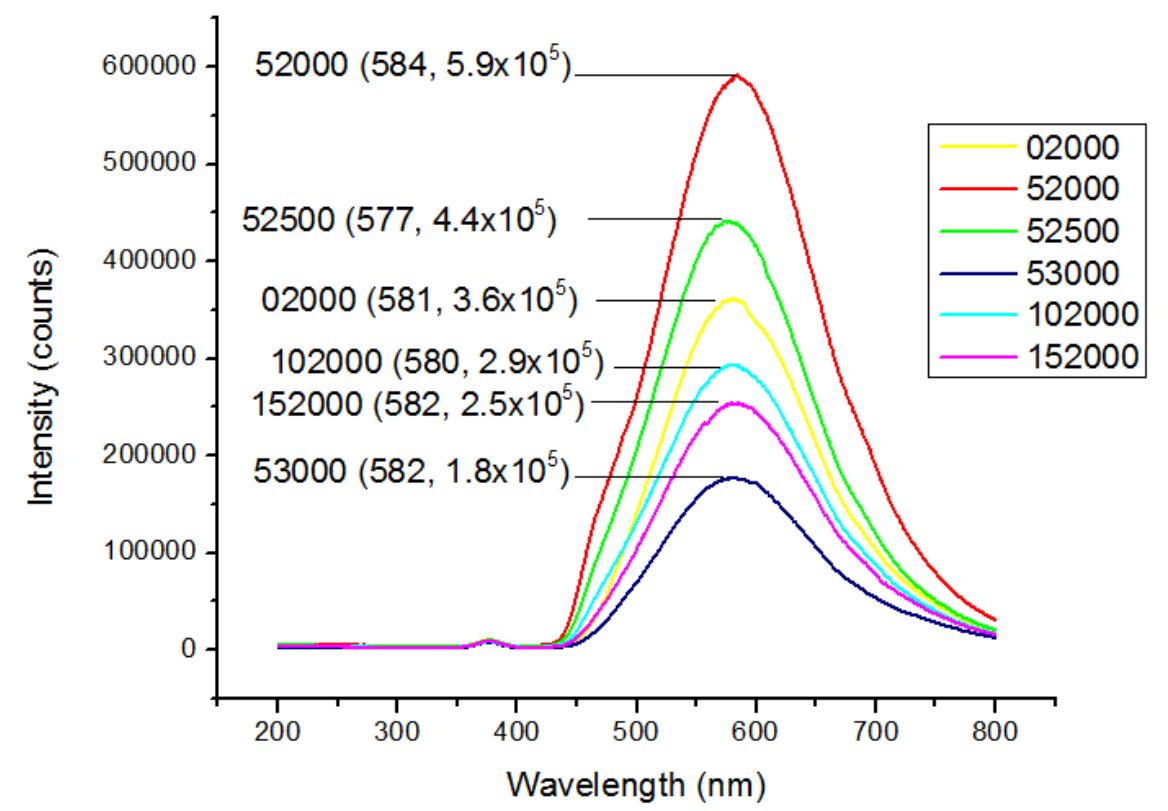

Figure 2. PL spectrum of $\mathrm{MgZnO}$ thin films with different spin rate and $\mathrm{Mg}$ contents

\section{XRD Analysis}

The XRD were used to analyze and determine the composition, phase exists and crystallite size of $\mathrm{Mg}$ doped $\mathrm{ZnO}$ sample. The crystallite size and d-spacing of $\mathrm{Mg}$ doped $\mathrm{ZnO}$ thin films were calculated from obtained XRD results. The d-spacing of thin films can be obtained from Bragg's Law which as shown in Eq. 2.

$$
d=\lambda /(2 \sin \theta)
$$

where $\lambda$ is the wavelength of X-ray $(0.15406 \mathrm{~nm}), d$ is d-spacing in nm, $\theta$ is the Bragg's angle, 2-theta $(2 \theta)$. The crystallite size was obtained by using Scherrer's formula, as shown in Eq 3.

$$
T=0.9 \lambda /(\beta \cos \theta)
$$

where $T$ is crystallite size in nanometer, $\beta$ is full width at half maximum of the peak (FWHM) in radian. In Figure 3 , the peak located at $\sim 78^{\circ}$, indicates aluminium peak originated from the substrate. The $\mathrm{ZnO}$ phase could be found in the thin 
film that oriented in (101) crystal planes at $\sim 38^{\circ}$. Besides, it could be preferentially oriented in (220) crystal plane at $\sim 65^{\circ}$, which corresponds to the $\mathrm{MgO}$ phase. Moreover, all samples doped with $\mathrm{Mg}$ show the $\mathrm{MgO}$ phase formation corresponding to the (220) crystal plane. Figure 3 shows the $\mathrm{MgO}$ phase presence, which represents by (220) crystal plane is formed when $\mathrm{Mg}$ ions were doped inside the $\mathrm{ZnO}$ crystal lattice. However, the $\mathrm{ZnO}$ phase is decreased after doping with $\mathrm{Mg}$ as the dopant ions may replace $\mathrm{Zn}$ ions due to their atomic radii variance and indicate a small amount of strain leads to change the regularity of crystal [2]. Table 2 shows the average crystallite size gradually decreases upon increasing $\mathrm{Mg}$ concentration.

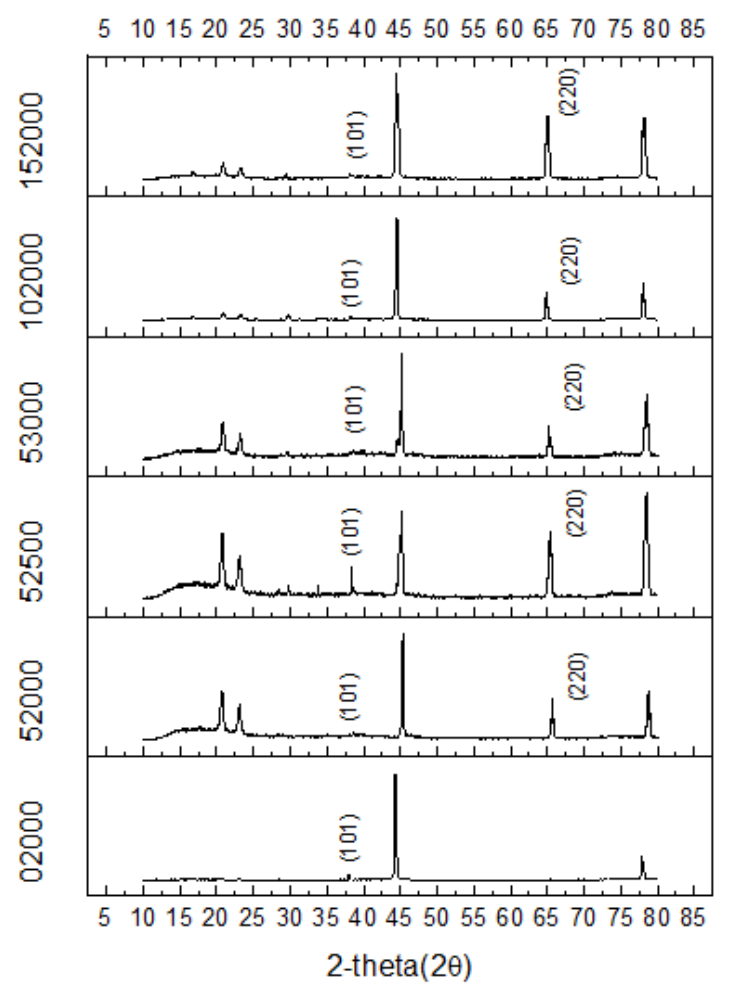

Figure 3. XRD spectrum of each film

Table 2. Crystallite size of diffractions (101) and (220) peaks for $\mathrm{MgZnO}$ thin films with different $\mathrm{Mg}$ contents and spin rate.

\begin{tabular}{cccc}
\hline Sample & $\begin{array}{c}2 \text {-theta } \\
(2 ?)\end{array}$ & $(\mathrm{h} \mathrm{k1})$ & $\begin{array}{c}\text { Crystallite } \\
\text { Size (nm) }\end{array}$ \\
\hline 02000 & 37.98 & $(101)$ & 94.46 \\
& - & - & - \\
52000 & 38.56 & $(101)$ & 4.92 \\
& 65.68 & $(220)$ & 63.48 \\
52500 & 38.34 & $(101)$ & 46.27 \\
& 65.46 & $(220)$ & 35.99 \\
53000 & 38.24 & $(101)$ & 2.45 \\
& 65.5 & $(220)$ & 31.40 \\
& & & \\
102000 & 38.3 & $(101)$ & 31.94 \\
& 64.94 & $(220)$ & 54.68 \\
& & & \\
152000 & 38.14 & $(101)$ & 28.73 \\
& 65.02 & $(220)$ & 24.50 \\
\hline
\end{tabular}

\section{Morphology Analysis}

FESEM was used to analyze and study the surface morphology of pure $\mathrm{ZnO}$ and $\mathrm{Mg}$ doped $\mathrm{ZnO}$ with different $\mathrm{Mg}$ concentrations and spin rate at constant heat treatment of $400{ }^{\circ} \mathrm{C}$. Surface morphology of $0 \mathrm{wt} \% \mathrm{Mg}$ and spin speed of $2000 \mathrm{rpm}$ at a different magnification at several regions of the samples (Figure 4). The result shows the small grains were formed with less porosity in the highest nano-sized measurement around $40 \mathrm{~nm}$ to $65 \mathrm{~nm}$. The surface morphology of 5 wt $\% \mathrm{Mg}$ and spin speed of $2000 \mathrm{rpm}$ shows the surface of samples appears more porosity and cracking structures with inhomogeneous distribution of nanoparticles was formed in highest measurement around $25 \mathrm{~nm}$ to $40 \mathrm{~nm}$ (Figure 5). Meanwhile, the surface morphology of $5 \mathrm{wt} \% \mathrm{Mg}$ and spin speed of $2500 \mathrm{rpm}$ shows the surface of samples appears clear circular-shaped nanoparticles, more compact and dense even though they have more porosity than $5 \mathrm{wt} \%$ and spin speed 
of $2000 \mathrm{rpm}$ (Figure 6). The highest grain size of nanoparticles was around $30 \mathrm{~nm}$ to $45 \mathrm{~nm}$. The sample of $5 \mathrm{wt} \% \mathrm{Mg}$ and spin speed of $3000 \mathrm{rpm}$ show the surface of samples possessed compact clear circular shapes nanoparticles better than 52000 and 525000 and dense distribution of crystalline structure (Figure 7). The highest grain size of the samples was around $20 \mathrm{~nm}$ to $60 \mathrm{~nm}$. Furthermore, the sample of $10 \mathrm{wt} \% \mathrm{Mg}$ and spin speed of $2000 \mathrm{rpm}$ shows the surface of samples consists less porosity, and cracking with a few agglomerations of nanoparticles was observed. The highest grain size of the nanoparticles was around $20 \mathrm{~nm}$ to $45 \mathrm{~nm}$ (Figure 8). Lastly, the sample of $15 \mathrm{wt} \% \mathrm{Mg}$ and spin speed of 2000 rpm appears inhomogeneous distribution with more agglomeration of nanoparticles was observed. The highest grain size of nanoparticles was around $20 \mathrm{~nm}$ to $60 \mathrm{~nm}$ (Figure 9).
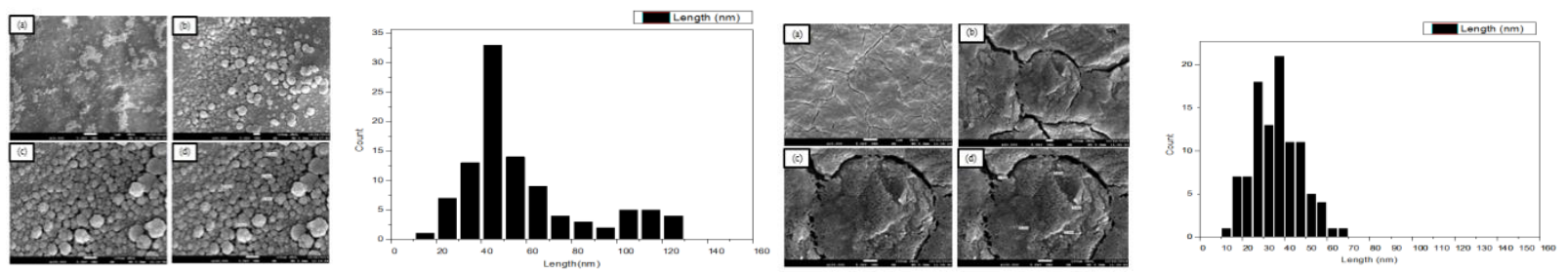

Figure 4. Surface morphology and particles size histogram of $\mathrm{ZnO}$ thin films deposited on $\mathrm{Al}$ foil with different magnification and spin rate of $2000 \mathrm{rpm}$ (a) $10 \mathrm{kx}$ (b) $50 \mathrm{kx}$ (c) $100 \mathrm{kx}$
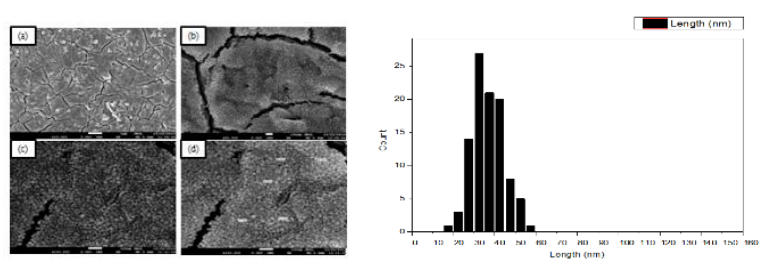

Figure 6. Surface morphology and particles size histogram of $5 \mathrm{wt} \% \mathrm{Mg}$ doped $\mathrm{ZnO}$ thin films deposited on $\mathrm{Al}$ foil with different magnification and spin rate of $2500 \mathrm{rpm}$ (a) $10 \mathrm{kx}$ (b) $50 \mathrm{kx}$ (c) $100 \mathrm{kx}$
Figure 5. Surface morphology and particles size histogram of $5 \mathrm{wt} \% \mathrm{Mg}$ doped $\mathrm{ZnO}$ thin films deposited on $\mathrm{Al}$ foil with different magnification and spin rate of $2000 \mathrm{rpm}$ (a) $10 \mathrm{kx}$ (b) $50 \mathrm{kx}$ (c) $100 \mathrm{kx}$
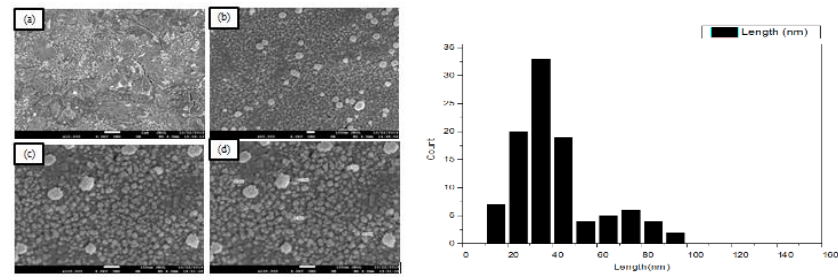
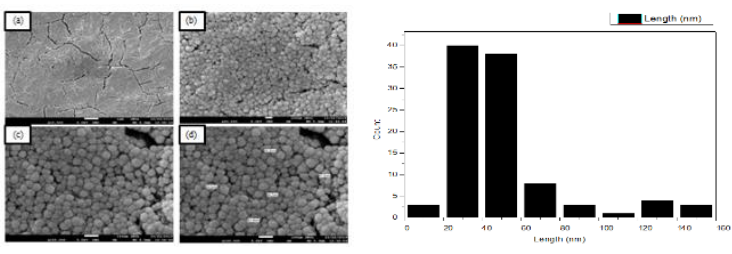

Figure 7. Surface morphology and particles size histogram of $5 \mathrm{wt} \% \mathrm{Mg}$ doped $\mathrm{ZnO}$ thin films deposited on $\mathrm{Al}$ foil with different magnification and spin rate of $3000 \mathrm{rpm}$ (a) $10 \mathrm{kx}$ (b) $50 \mathrm{kx}$ (c) $100 \mathrm{kx}$
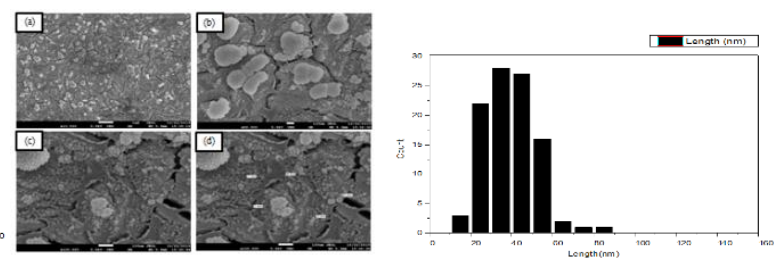

Figure 9. Surface morphology and particles size histogram of $15 \mathrm{wt} \% \mathrm{Mg}$ doped $\mathrm{ZnO}$ thin films deposited on $\mathrm{Al}$ foil with different magnification and spin rate of $2000 \mathrm{rpm}$ (a) $10 \mathrm{kx}$ (b) $50 \mathrm{kx}$ (c) $100 \mathrm{kx}$

\section{Piezoelectric Properties Analysis}

The piezoelectric properties analysis was conducted by using ultrasonic vibrator and multimeter. Piezoelectric material was able to generate electricity when stress is applied. The vibration generates by the ultrasonic cleaner produced a potential difference for each sample. The potential difference of $\mathrm{Mg}$ doped $\mathrm{ZnO}$ thin film with different $\mathrm{Mg}$ contents and spin rate was summarized in Table 3. The value of potential difference increased, the resistivity value also increased as the $\mathrm{Mg}$ contents increased. According to previous work, $\mathrm{Mg}$ incorporated in $\mathrm{ZnO}$ crystals not only increased the grain boundary area to form electrical barriers and carriers dispersion but also reduced oxygen defects as the $\mathrm{Mg}-\mathrm{O}$ bond has a more ionic character than the $\mathrm{Zn}-\mathrm{O}$ bond, which reduced the concentration of electrons and increased resistivity at the same time [8]. The potential difference value increased as the spin speed increased. The film thickness will be thinner when fabricated at the higher spin speed causes the area of thin films to become larger. In spin coating, rapid solvent evaporation causes rapid molecular aggregation, which often induces the lattice strain in the grown film. In some situations, the metastable phase will appear in the film, making the molecular orientation desirable for charge transport $[8]$. 
Table 3. The potential difference of $\mathrm{MgZnO}$ thin film with different $\mathrm{Mg}$ contents and spin rate.

\begin{tabular}{cc}
\hline Samples & Potential Difference $(\mathbf{V})$ \\
\hline 02000 & 0.056 \\
52000 & 0.2549 \\
52500 & 0.3095 \\
53000 & 0.4314 \\
102000 & 0.4433 \\
152000 & 0.4919 \\
\hline
\end{tabular}

\section{CONCLUSION}

Conclusively, using sol-gel spin coating techniques, pure $\mathrm{ZnO}$ and doped with different $\mathrm{Mg}$ content and spin rate rotation were successfully synthesized. The effect of $\mathrm{Mg}$ doped $\mathrm{ZnO}$ has been studied on it structural and physical properties. XRD analysis results with diffraction phases of the crystal plane of (101) representing ZnO phases while (220) for $\mathrm{MgO}$ phases respectively. Besides, FESEM reveals that thin film composition is spherical inhomogeneous nanoparticles with an average range of 20 to $60 \mathrm{~nm}$. Other than that, $\mathrm{Mg}$ doped $\mathrm{ZnO}$ transmission spectroscopies showed that $\mathrm{Mg}$ doping in $\mathrm{ZnO}$ improved the UV wavelength transmission. Doping also raised the zinc oxide bandgap for the 15 wt\% sample. PL spectra demonstrate the emitted electron at two emission bands: UV range ( $370 \mathrm{~nm})$ and visible range $(\sim 584 \mathrm{~nm})$ for all samples. Mg doping also increased potential differences in term of piezoelectric properties. The results obtained by changing spin speed shows $5 \mathrm{wt} \% \mathrm{Mg}$ doped $\mathrm{ZnO}$ fabricated with $3000 \mathrm{rpm}$ has better results in term of characterization FESEM, UV-Vis, PL and piezoelectric properties since it has good surface morphology with uniform and dense distribution of nanoparticles, large optical bandgap energy, low intensity of PL peaks and higher potential difference among 52000 and 52500. For photonic application, the 52000 sample has the best result in PL characterization since it has the highest intensity of peaks. Moreover, 152000 samples show the best results in changing Mg concentration since it has the highest intensity of crystallite peaks, larger optical band gap energy, lower intensity of PL, and higher potential difference among the other concentration of $\mathrm{Mg}$ content.

\section{ACKNOWLEDGEMENT}

This research was supported by Fundamental Research Grant Scheme (FRGS) Malaysia No. FRGS/1/2019/TK05/UMP/ 02/20 (RDU1901219).

\section{REFERENCES}

[1] Ajadi, D. A., Agboola, S. M., \& Adedokun, O. (2016). Effect of Spin Coating Speed on Some Optical Properties of ZnO Thin Films. Journal of Materials Science and Chemical Engineering, 04(05), 1-6. https://doi.org/10.4236/msce.2016.45001

[2] Hashim, N. H., Subramani, S., Devarajan, M., \& Ibrahim, A. R. (2017). Properties of undoped ZnO and Mg doped ZnO thin films by sol-gel method for optoelectronic applications. Journal of the Australian Ceramic Society, 53(2), 421-431. https://doi.org/10.1007/s41779-017-0051-9

[3] Johari, S., Muhammad, N. Y., \& Zakaria, M. R. (2017). Study of zinc oxide thin film characteristics. EPJ Web of Conferences, 162, 01057. https://doi.org/10.1051/epjconf/201716201057

[4] Kotsuki, K., Tanaka, H., Obata, S., Stauss, S., Terashima, K., \& Saiki, K. (2014). The importance of spinning speed in fabrication of spin-coated organic thin film transistors: Film morphology and field effect mobility. Applied Physics Letters, 104(23). https://doi.org/10.1063/1.4883216

[5] Mohd Arif, N. A. A., Jiun, C. C., \& Shaari, S. (2017). Effect of Annealing Temperature and Spin Coating Speed on MnDoped ZnS Nanocrystals Thin Film by Spin Coating. Journal of Nanomaterials, 2017. https://doi.org/10.1155/2017/2560436

[6] Singh, J., Kumar, P., Hui, K. S., Ramam, K., Tiwaria, R. S. and Srivastava, O. N. (2012). Synthesis, band-gap tuning, structural and optical investigations of $\mathrm{Mg}$ doped $\mathrm{ZnO}$ nanowires. CrystEngComm, 14, 5898-5904. DOI: $10.1039 / \mathrm{c} 2 \mathrm{ce} 06650 \mathrm{e}$.

[7] Pradeev raj, K., Sadaiyandi, K., Kennedy, A., Sagadevan, S., Chowdhury, Z. Z., Johan, M. R., Abdul Aziz, F., Rafique, R. F., Selvi, R. T., and Rathina Bala, R (2018). Influence of Mg Doping on ZnO Nanoparticles for Enhanced Photocatalytic Evaluation and Antibacterial Analysis. Nanoscale Research Letters, 13. https://doi.org/10.1186/s11671-018-2643-x

[8] Tsay, C. Y., Chen, S. T., \& Fan, M. T. (2019). Solution-processed Mg-substituted ZnO thin films for metal-semiconductormetal visible-blind photodetectors. Coatings, 9(4). https://doi.org/10.3390/COATINGS9040277 